\title{
UN DISCURSO SANITARIO PARA UN PROYECTO POLÍTICO. LA EDUCACIÓN SANITARIA EN LOS MEDIOS DE COMUNICACIÓN DE MASAS DURANTE EL PRIMER FRANQUISMO
}

\author{
Isabel Jiménez Lucena \\ $\mathrm{M}^{\mathrm{a}}$ José Ruiz Somavilla \\ Jesús Castellanos Guerrero \\ Historia de la Ciencia \\ Facultad de Medicina, Universidad de Málaga
}

\section{RESUMEN}

El análisis de los discursos expuestos en un ciclo de conferencias radiadas durante los años 1939-1940 en la ciudad de Málaga sobre higiene materno-infantil, organizado por la Jefatura Provincial de Sanidad, nos permite poner de manifiesto cómo se utiliza un recurso como la divulgación de contenidos sanitarios como parte de un proyecto político, el nacional-sindicalismo, al que sirvió como elemento vehiculizador.

PALABRAS CLAVE: educación sanitaria, divulgación de la medicina, España, franquismo.

\section{SUMMARY}

Making used of the radio conferences organized by «Jefatura Provincial de Sanidad» of Málaga during 1939 and 1940 on maternal and infant hygiene, which were published, in this study we analyse the relationship between politics and health education. The article show how the popularization of medicine was a resource used by national-syndicalism more than sanitary information for the population during early years of Francoism.

KEY WORDS: health education, popularization of medicine, Spain, francoism.

1. CONSIDERACIONES PREVIAS. LAS COORDENADAS SOCIO-SANITARIAS Y EL DISCURSO DE EDUCACIÓN SANITARIA.

En 1939, tras la guerra civil, se produjo en España una situación de crisis generalizada. En este contexto, la sociedad malagueña comenzó este periodo en unas condi- 
ciones estructurales y coyunturales muy precarias. Durante esta etapa histórica, el secular problema de la escasez de viviendas en la capital malagueña se agravó, debido a la destrucción de edificios durante los acontecimientos bélicos y al desplazamiento de población que se produjo hacia la capital malagueña. El problema de la vivienda en Málaga era tanto cuantitativo como cualitativo, pues existía un importante déficit de salubridad de un elevado porcentaje de las viviendas. Los núcleos de infraviviendas aumentaron, y en ellos la vida transcurría bajo un estado de extrema miseria, de forma muy similar se vivía en los barrios obreros: hacinamiento, deficiencias extremas en los sistemas de abastecimiento de agua y evacuación de excretas $^{1}$. Otro aspecto de la situación vivida fue el relacionado con la alimentación. La crisis estructural de la agricultura con la consiguiente escasez de alimentos y la imposición de un estricto sistema de racionamiento que desembocó en la aparición de un «mercado negro», donde los precios de los productos de primera necesidad, ya de por sí elevados, alcanzaron cifras muy altas; esto junto a los bajos salarios del momento, provocó dificultad, cuando no imposibilidad, para acceder a los productos necesarios para la supervivencia. Esta fue una época de «infranutrición endémica en los medios populares $»^{2}$.

Reflejo de esta situación fueron las irrupciones de brotes epidémicos de viruela, difteria y tifus exantemático ${ }^{3}$ y los incrementos de las cifras de mortalidad general, mortalidad por causa infecciosa y mortalidad infantil: esta última alcanzó en 1941 cifras características de la primera mitad de la década de los años veinte con una tasa de 132,4 muertes de menores de un año por cada mil nacidos vivos en la capital malagueña y de 157,2 en la provincia ${ }^{4}$.

Las respuestas que desde el ámbito médico-sanitario se dieron ante la realidad socio-sanitaria de la Málaga de la posguerra estuvieron muy marcadas por las circunstancias políticas del momento. La capacidad de respuesta del sistema asistencial ante la crisis sanitaria fue muy reducida, la escasez de medios infraestructurales, materiales y de personal caracterizaron a la organización sanitaria de la posguerra ${ }^{5}$.

\footnotetext{
1 Una descripción más detallada de esta situación puede encontrarse en JIMÉNEZ LUCENA, I. (1990), El tifus en la Málaga de la posguerra. Un estudio histórico médico en torno a una enfermedad colectiva, Málaga, Universidad de Málaga, pp. 18-21.

2 Ibid., pp. 21-23.

3 Con relación a estos acontecimientos pueden verse la obra antes citada y las descripciones que de los mismos hizo el entonces Director General de Sanidad: PALANCA, J. A. (1943), Las epidemias de la postguerra. Discurso leído en la solemne sesión celebrada el día 28 de Marzo de 1943 en la Real Academia de Medicina, Madrid, Instituto de España.

4 Para un desarrollo más amplio de este aspecto véase JIMÉNEZ LUCENA, I. (1989), Enfermedad y sociedad en la Málaga de la postguerra: el tifus exantemático, Málaga, Universidad de Málaga, Tesis de licenciatura, pp. 21-38.

5 Esto que decimos se puso de manifiesto, especialmente, durante la epidemia de tifus exantemático que se desarrolló en los primeros años de posguerra; véase JIMÉNEZ LUCENA, I. (1990), pp. 23-25, 48-56 y 70-88.
} 
En estas circunstancias, como han puesto de manifiesto diversos autores ${ }^{6}$, la literatura de divulgación higiénico-sanitaria es especialmente utilizada. Sin embargo, este tipo de actividad no es sólo de índole informativa, sino que, como ha sido ampliamente señalado en distintos estudios, es un instrumento político que los diferentes grupos sociales y regímenes utilizan para difundir su modelo de sociedad ${ }^{7}$. Parece evidente, por tanto, que las fuerzas sociales hegemónicas impregnaran las campañas de educación sanitaria con sus ideas y objetivos.

Enseñarles cómo vivir, a la población en general, ha sido el principal objetivo de la divulgación médico-sanitaria ${ }^{8}$. Y ese cómo vivir implica comportamientos sociales y políticos, actitudes y valores determinados. ¿Qué comportamientos, actitudes y valores son los saludables?. Eso, sostenemos, estará estrechamente relacionado con los intereses políticos y sociales de los grupos hegemónicos. En este trabajo de aproximación al estudio de la utilización de las campañas de educación sanitaria con objetivos políticos, nos proponemos analizar cómo a través de un discurso higiénicosanitario, supuestamente científico, se crean imágenes de la realidad que benefician a los gobernantes ${ }^{9}$; cómo las preocupaciones sobre la salud y la enfermedad que, de forma implícita o explícita, se exponen corresponden a intereses políticos e ideológicos más que a preocupaciones reales por el estado de salud de la población; cómo cuando se habla de las soluciones posibles van más enfocadas a obtener determinadas actitudes de adhesión política a las fuerzas gobernantes y sometimiento y obediencia a los expertos que a solucionar problemas de tipo sanitario, dada la falta de adecuación de las propuestas a la realidad socioeconómica de la mayoría de la población. Para ello, hemos analizado los discursos emitidos por un medio de comunicación de masas, la radio, durante una campaña de educación sanitaria.

\footnotetext{
6 Véanse PORTER, R. (ed.) (1992), The popularization of Medicine, 1650-1850, London-New York, Routledge y FuENTES CABALlERO, M. T. (1996), «Costumbres privadas e interés público. La lactancia materna en la literatura médica de divulgación. Barcelona, 1880-1890», Dynamis, 16, 369-397, pp. 379-80.

7 Esto lo hemos podido observar en el análisis realizado acerca de los discursos sobre la educación sanitaria que los diferentes grupos ideológicos y sociales expusieron durante el periodo de la Segunda República. Véase JIMÉNEZ LuCENA, I. (1995), Cambio político y alternativas sanitarias: el debate sanitario en la II República, Málaga, Universidad de Málaga. Tesis de doctorado, pp. 142-148, 188-192, 239240 y $276-281$

8 NEVEN, M.; ORIS, M. (1996), «Santé et citoyenneté dans la Belgique contemporaine», Dynamis, $16,399-426$, p. 415

9 Sobre este aspecto puede verse JIMÉNEZ LUCENA, I. (1994), «El tifus exantemático de la posguerra española (1939-1943). El uso de una enfermedad colectiva en la legitimación del «Nuevo Estado»«, Dynamis, 14, 185-198.
} 


\section{LAS CARACTERÍSTICAS DE LA CAMPAÑA DE EDUCACIÓN SANITARIA}

Los medios de comunicación de masas han actuado como agente de la historia en tanto que han influido de manera notable en la configuración política y cultural de las sociedades ${ }^{10}$. Algunos autores consideran que la sociedad moderna no sería lo que es sin los medios sonoros y visuales de comunicación, pues el tipo de información que emiten se integra en la vida cotidiana y en la percepción de la propia sociedad ${ }^{11}$. Concretamente la radio ha estado y está en muchos aspectos en primer plano de la acción política y social ${ }^{12}$. Una de las razones para esto puede ser que, como Roger Egeter sostiene, «tanto la imagen como el sonido son medios que infunden una gran sensación de credibilidad $»^{13}$; de ahí la importancia que los medios sonoros y visuales tienen en los procesos de divulgación.

En este sentido, un importante elemento de interés en este estudio concreto es el hecho de que se usara la radio como medio de divulgación. La popularización médica tenía hasta esos momentos, como es bien conocido, una tradición escrita concretada en manuales, prensa y carteles. La radio puso en manos de los expertos el mecanismo de transmisión oral, que hasta entonces había sido considerado de forma ambivalente. Como sostiene Enrique Perdiguero, si bien era reconocido como «el único posible para extender el conocimiento a todos los rincones», a la vez, era «sospechoso de servir de vía de difusión de preocupaciones y errores vulgares ${ }^{14}$, debido a que en la inmensa mayoría de los casos ese mecanismo de transmisión estaba fuera del control de los expertos. El poder de la radio como medio de comunicación de amplia difusión e instrumentalizable como "arma de propaganda» había sido apreciado por gobernantes y grupos políticos muy poco tiempo después de que las ondas radiofónicas empezaran a funcionar, en la década de los años veinte ${ }^{15}$. Este potencial fue cada vez más utilizado, llegando, durante la guerra civil, a ser la radio el principal medio de difusión para informar, dar órdenes y consignas ${ }^{16}$. Como medio de comunicación entre los expertos en cuestiones médico-sanitarias y la población, la radio había sido

\footnotetext{
10 BASSETS, P. L. (1981), «La ràdio com a document i com a agent de la història», L'avenç, $\mathrm{n}^{\circ}$ 44, 58-61.

11 Egeter VAN KUYK, R. H. J. (1994), «Los medios audiovisuales: ¿cómo y por qué?», Historia y Fuente Oral, n ${ }^{\circ} 11,165-169$

12 BASSETS, P. L. (1981)

13 Egeter VAN KuYK, R. H. J. (1994), p. 166.

14 Perdiguero, E. (1995), «Popularización de la higiene en los manuales de economía doméstica en el tránsito de los siglos XIX al XX», en J. L. Barona, (ed.) Malaltia i cultura, Valencia, Trobades. Seminari d'Estudis sobre la Ciència, p. 231.

15 Sobre este aspecto pueden verse GARITAONAINDIA, C. (1988), La radio en España (1923-1939), Leioa, Universidad del País Vasco, y DíAZ, L. (1992), La radio en España, 1923-1993, Madrid, Alianza Editorial, pp. 90 y ss.

16 DÍAZ, L. (1992), pp. 121-8
} 
utilizada durante la Segunda República como han señalado Jorge Molero Mesa y Esteban Rodríguez Ocaña ${ }^{17}$. En estos momentos de la posguerra, la necesidad de dar al pueblo una educación sanitaria, así como la utilización de la radio como medio más adecuado para ello, quedó explícita en el discurso de Salvador Almansa: «Nada más oportuno que la Radio, para hacer llegar a las entrañas del pueblo las ideas básicas, vulgarizando los hechos y conocimientos científicos, para propagar las medidas higiénicas a fin de crear un ambiente social, una cultura antituberculosa, que saque de la ignorancia en estos problemas» ${ }^{18}$. Pero, como veremos, la divulgación sanitaria iba más allá de esto, participando en un proyecto ideológico y persiguiendo, implícita y explícitamente, objetivos políticos concretos.

Nuestro análisis se centrará en el conjunto de conferencias radiadas que fueron posteriormente publicadas por los Servicios Provinciales de Sanidad Infantil y Maternal de la Jefatura Provincial de Sanidad. El lema que aparece en la portada de la publicación que utilizamos en este trabajo era el que presidía la campaña de la que formaban parte las conferencias: «iAl servicio de España y del niño Español!» ${ }^{19}$.

La publicación se inicia con una Introducción de Salvador Marina (Jefe del Servicio Provincial de Sanidad Infantil y Maternal) en la que se señalaba que estas conferencias se emitieron por radio en 1940 y algunas (no dice cuáles) en años anteriores, es decir entre 1938 y 1939. A éstas se une en la publicación el discurso que Francisco de Agramonte (diplomático) dio «a las señoras y señoritas que tomaron parte en el segundo cursillo de Iniciación de Puericultura» del año 1939.

Tanto las conferencias que recoge como la misma publicación tenían por objeto, según el introductor de la obra, «divulgar los conocimientos indispensables para llevar a cabo la correcta alimentación e higiene del niño»; cuestión ésta en la que la divulgación higiénico-sanitaria ha estado especialmente interesada, como han puesto de manifiesto diversos trabajos ${ }^{20}$. Con esa finalidad tuvieron lugar: dos conferencias

17 Rodríguez OcAÑA, E.; MOLero MESA, J. (1993), «La cruzada por la salud. Las campañas sanitarias del primer tercio del siglo XX en la construcción de la cultura de la salud», en MONTIEL, L., La salud en el estado de bienestar. Análisis histórico, Madrid, Editorial Complutense, p. 146.

18 Almansa DE CARA, S. (1941a), «La adquisición de la tuberculosis en los niños», en Servicios Provinciales de Sanidad Infantil y Maternal, Conferencias radiadas de Puericultura, Málaga, Jefatura Provincial de Sanidad, p. 25.

19 Elementos de esta campaña han sido recientemente analizados en BERNABEU-MESTRE, J.; PERDIGUERO GIL, E. (1998), «At the Service of Spain and Spanish Children; Mother and Child Health Care in Spain During the First Years of Franco's Regime». Ponencia presentada en Conference «Science, Public Policy and Health in Europe», organizada por la Universitat Autònoma de Barcelona, Barcelona, 25-28 de noviembre de 1998.

20 A este respecto pueden verse entre otros: PERDiguero, E. (1993), «La popularització dels conexisements científico-mèdics a la Restauració: el cas de la premsa periòdica d'Alacant», en NAVARRO, V., et al. (coords.), II Trobades d'Història de la Ciència i de la Técnica, Barcelona, Societat Catalana d'Història de la Ciència i de la Tècnica, pp. 171-180; CABALlERO, M. T. (1996). En RODRÍGUEZ OCAÑA, E.; Molero MesA, J. (1993), se pone de manifiesto que entre las campañas médico-sociales, de las que 
de puericultura general a cargo de Salvador Marina y Gregorio Marina ${ }^{21}$; una conferencia sobre vacunas de Honorato Vidal Juárez ${ }^{22}$; dos conferencias acerca de maternología e higiene prenatal de José Luis Oliva ${ }^{23}$; tres conferencias relacionadas con el problema de la tuberculosis, todas ellas dadas por Salvador Almanza ${ }^{24}$; lactancia y alimentación fueron temas abordados en tres conferencias a cargo de Gregorio Marina, P. Ruiz Montosa y J. Mowbray ${ }^{25}$; una conferencia se ocupó de los tratamientos digestivos, siendo Salvador Marina quien se ocupó de la misma ${ }^{26}$; la odontología fue tratada por Fernando Roldán en una de las emisiones ${ }^{27}$; el raquitismo estuvo también presente en una conferencia de Salvador Marina ${ }^{28}$ y la correcta educación del niño se

formaría parte la educación higiénico-sanitaria, más importantes que se pusieron en marcha durante el primer tercio del siglo XX la desarrollada contra la mortalidad infantil fue una de ellas. En este sentido, es de interés la reciente publicación RODRÍGUEZ OCAÑA, E. (1999), «La construcción de la salud infantil. Ciencia, medicina y educación en la transición sanitaria en España», Historia Contemporánea, nº 18, 19-52.

21 MARINA, S. (1941a), «Necesidad de atender cuidadosamente a los niños para disminuir la alta cifra de mortalidad infantil existente», en Servicios Provinciales de Sanidad Infantil y Maternal, pp. 5-7 y MARINA, G. (1941a), «Cuidados del niño en caso de enfermedad. Peligros de los cuidados caseros», en Servicios Provinciales de Sanidad Infantil y Maternal, pp. 65-69.

Salvador Marina era en aquellos momentos Jefe del Servicio Provincial de Sanidad Infantil y Maternal y Gregorio Marina Director del Centro de Alimentación Infantil de Auxilio Social y Médico Ayudante de los Servicios Provinciales de Sanidad Infantil y Maternal.

22 VidAl JuÁREZ, H. (1941), «Vacunaciones en la infancia», en Servicios Provinciales de Sanidad Infantil y Maternal, pp. 8-15. Honorato Vidal era el Jefe Provincial de Sanidad de Málaga.

23 OLIVA, J. L. (1941a), «Vigilancia médica del embarazo. Su importancia en la defensa de la madre y del hijo», en Servicios Provinciales de Sanidad Infantil y Maternal, pp. 16-20 y (1941b), «Peligros del trabajo femenino en relación con la maternidad», en Ibidem, pp. 21-24.

José Luis Oliva desempeñaba en aquellos momentos los cargos de Tocólogo-consultor del Servicio Maternal e Infantil del Seguro de Maternidad de la Beneficencia Municipal y de los Servicios Provinciales de Sanidad Infantil y Maternal.

24 Almansa de CARA, S. (1941a), pp. 25-29; (1941b) «Manera de evitar la tuberculosis en los niños», en Ibidem, pp. 30-34 y (1941c) «La playa, los baños de mar y la tuberculosis infantil», en Ibidem, pp. 38-42.

Salvador Almansa era Jefe de la Lucha Antituberculosa Provincial de Málaga.

25 MARINA, G. (1941b), «La lactancia materna es la base de la buena crianza y del perfecto desarro1 lo del niño», en Servicios Provinciales de Sanidad Infantil y Maternal, pp. 43-47; RUIZ MONTOSA, P. (1941), «Lactancia artificial y mixta», en Ibidem, pp. 48- 53 y MOWBRAY BARBERÁN, J. (1941), «Destete. Alimentación en el segundo año de la vida», en Ibidem, pp. 54-59.

Pedro Ruiz Montosa era Médico Ayudante de los Servicios Provinciales de Sanidad Infantil y Maternal. Julio Mowbray era Director del Centro de Control Sanitario de Auxilio Social y Médico Ayudante de los Servicios Provinciales de Sanidad Infantil y Maternal.

26 MARINA, S. (1941b), «El calor favorece la producción de trastornos digestivos de los niños. Manera de prevenirlos», en Servicios Provinciales de Sanidad Infantil y Maternal, pp. 35-37.

27 ROLDÁn ANDREU, F. (1941), «Cuidados que requiere la boca del niño», en Servicios Provinciales de Sanidad Infantil y Maternal, pp. 60-64.

Fernando Roldán era odontólogo del Instituto Provincial de Higiene de Málaga.

28 MARINA, S. (1941c), "Qué es el raquitismo y cómo evitarlo», en Servicios Provinciales de Sanidad Infantil y Maternal, pp. 70-72. 
trató en la emisión de Francisco de Agramonte ${ }^{29}$. Este último conferenciante fue el autor de las páginas finales de la publicación que recogió los discursos emitidos durante la campaña, con su ya mencionada conferencia a las participantes del segundo cursillo de Iniciación de Puericultura ${ }^{30}$.

Si tuviéramos que valorar la importancia que se les dio a los distintos temas por la extensión que tuvieron, la lactancia y alimentación, la educación infantil y el problema de la tuberculosis ocuparían el primer lugar. Higiene prenatal y maternología les seguiría en importancia. Consejos de puericultura general y vacunas irían detrás. Y, con un interés, en atención a su extensión, bastante menor se divulgaron aspectos relacionados con el cuidado de la boca del niño, el raquitismo y los trastornos digestivos.

En otro orden de cosas, si hubiésemos de calificar las charlas emitidas no por la intención explicitada sino por las características del discurso producido, algunas de ellas quedarían excluidas del género divulgativo ${ }^{31}$. En este sentido, la conferencia de Honorato Vidal, sobre las vacunas antivariólica, antidiftérica, antituberculosa y antitífica, difícilmente podría ser divulgativa, pues, aunque él la calificara de «sencilla charla», los términos que utilizó eran muy técnicos, propios de profesionales de la medicina: inyección de antitoxina o de anatoxina diftérica, inyección subcutánea o intramuscular, profilaxis, vacuna polivalente T.A.B., periodo de inoculación de la viruela, entre otros. Conferencias como las de Gregorio Marina o Ruiz Montosa, si bien no tuvieron un carácter tan técnico en su totalidad como la de Vidal Juárez, presentaron también previsibles dificultades de comprensión debido a la utilización de tecnicismos como «cualidades inmunizantes»o «panículo adiposo»» ${ }^{32}$, «impurezas bacterianas» ${ }^{33}$, «antitérmicos», «fontanela mayor», «dieta hídrica» ${ }^{34}$. Estos son sólo algunos ejemplos que muestran la escasa adaptación de buena parte del discurso experto al habla común.

29 Agramonte, F. de (1941a), «La educación del niño», en Servicios Provinciales de Sanidad Infantil y Maternal, pp. 73-77.

Francisco de Agramonte se presenta como Diplomático.

30 Agramonte, F. de (1941b), «El niño en el nuevo Estado Nacional-Sindicalista», en Servicios Provinciales de Sanidad Infantil y Maternal.

31 Si entendemos que la divulgación es la transmisión eficaz de la información, es necesario que el divulgador conozca y emplee los esquemas conceptuales y verbales del receptor. En palabras de Manuel Calvo, «divulgar es comunicar y la comunicación presupone un lenguaje común» CALVO HERNANDO, M. (1989), Civilización tecnológica e información, Barcelona, Asesoría Técnica de Ediciones, p. 35.

32 MARINA, G. (1941b).

33 Ruiz Montosa, P. (1941).

34 MARINA, G. (1941a). 


\section{LA IMAGEN DE LA REALIDAD ELABORADA EN EL DISCURSO DE DIVULGACIÓN}

En una coyuntura histórica en la que buena parte de los problemas sanitarios existentes, más arriba señalados, eran consecuencia de los acontecimientos bélicos que habían tenido lugar a causa del alzamiento militar propiciado por los grupos sociales que, durante el periodo analizado, ocupaban el poder, las ventajas que en aquellos momentos tenía desplazar la atención del contexto social al comportamiento individual en la explicación de la situación sanitaria eran evidentes.

En este sentido, se emitieron discursos que identificaban distintos niveles de responsabilización. Así, se llegó a plantear como la causa principal de la situación de España en aquellos momentos la mala educación de los niños que había llevado a que durante el gobierno republicano «iTodos se hicieron comunistas!» ${ }^{35}$. Además, como «los padres tenían otras cosas que atraían con mayor fuerza su atención [y] los funcionarios de la Beneficencia se encogían de hombros», los niños «morían en serie» ${ }^{36}$. Por ello, se sostenía que «en España, de los padres y madres hay que esperar poco. Generalmente, no saben serlo» ${ }^{37}$.

Siguiendo la tradición de las obras de divulgación decimonónicas y de principios de siglo, se mantenía que las altas cifras de mortalidad infantil tenían como causa la ignorancia de las sencillas reglas y preceptos de Puericultura que ponía al niño «en trance de enfermar y morir» ${ }^{38}$. Ignorancia que podía dar lugar a situaciones como las que Almansa describía, utilizando mecanismos alarmistas, en cuanto a contagio, y tenebrosidad en las imágenes descritas: «es la nodriza que amamanta al niño, quien al pretender darle la vida, prepara la muerte con su infección, o el abuelo catarroso, que tantas veces con sus caricias, trueca la alegría del nietecillo, en una trágica mueca de meningitis. Es la dama que va al matrimonio en pos de una progenie robusta y tiempo después, vé roto su hogar con hijos raquíticos, minorados y enfermos. Y otras veces en fin, es el Maestro que al despertar nuevas reflexiones en el escolar, abre a la vez, una mortífera brecha en su respiración [...] bastando a veces el espacio de un beso, para que haciendo contacto con el bacilo tuberculoso, una sola vez, quede para siempre infectado ${ }^{39}$.

35 AGRAMONTE, F. (1941b), p. 86.

36 Ibid., p. 80 .

37 Ibid., p. 83

38 MARINA, S. (1941a), p. 5. Con relación a la culpabilización de la población de las muerte infantiles en un periodo histórico anterior puede verse PERDIGUERO GIL, E.; BERNABEU MestRE, J. (1997), «Burlarse de lo cómico nacido de la tontería humana: el papel otorgado a la población por la divulgación higiénico-sanitaria durante la Restauración», en MONTIEL, L.; PORRAS, I. (coords.), De la culpabilización Individual a la Culpabilización de la Víctima. El papel del paciente en la prevención de la enfermedad, Madrid, Doce Calles, pp. 55-66.

39 Almansa DE CARA, S. (1941a), pp. 25-6. 
Pero, de todos los posibles culpables las máximas responsables eran las madres ${ }^{40}$ que habían «ignorado, casi en su totalidad, las más elementales nociones de la Puericultura». De ahí que incluso «los niños ricos» murieran en proporciones elevadas debido a que se encontraban: «comiendo lo que se les antoja, abrumados de lanas en cuanto estornudan o atiborrados de medicinas a veces inoportunas o excesivas, por sus madres, juguetes del empirismo y de la curandería más o menos disfrazadas. Luego se crían enclenques y mañosos, o dan un contingente enojoso a los estados intersexuales de que nos habla el Dr. Marañón $»^{41}$. Las madres tendrían una especial responsabilidad; entre otras cuestiones: «jamás una madre debe consentir que su hijo sea besado por individuos enfermos o sospechosos de estarlo», y «dejar que un niño juegue en el suelo, es un descuido lamentable, si se trata de una madre, será una ignorante desaprensiva» ${ }^{42}$.

Algunos autores aún afinaban más y aseguraban que eran las mujeres de las clases subordinadas las de conducta irresponsable más extendida, las que se dejaban en mayor número «influenciar por los consejos casi siempre perjudiciales para el niño, de las vecinas y comadres del barrio, que de todo quieren saber y tener experiencia y que tantos estragos causan entre los niños» ${ }^{43}$. Y es que, según el tocólogo que participaba en la campaña, las mujeres de las clases obreras en Andalucía eran especialmente indolentes y fanáticas ${ }^{44}$. Así, el mayor obstáculo para el progreso sanitario quedó bien definido. Con relación a este aspecto hemos podido apreciar que no había ninguna cortapisa en acusar directamente a las mujeres de las «clases humildes» de determinadas conductas antihigiénicas. Sin embargo, no se mencionaba de forma explícita a las mujeres de las clases acomodadas cuando se hacía referencia a conductas consideradas erradas que, por el contexto que rodeaba a la exposición, podrían relacionarse claramente con ámbitos sociales acomodados; este fue el caso, por ejemplo, de la siguiente situación: «la madre no padeciendo defectos ni imposibilidad física alguna, abandona la alimentación del niño en manos de otra persona, con objeto de disponer ella de más tiempo para hacer su acostumbrada vida de sociedad ${ }^{45}$.

Por otra parte, de todos los elementos que constituían los factores de la vida sana, era en la alimentación donde se cometían los «principales errores», pues era «corrientísimo que por mala dirección en unos casos, por inconstancia o poco deseo de sacrificarse en otros, algunas madres dejan de cumplir la sagrada misión de alimentar

\footnotetext{
40 Tradicionalmente las mujeres han sido encargadas de la labor del cuidado de la salud de los miembros de la familia, sobre todo de los hijos, y, por tanto, a ellas se las culpabilizó directamente de las enfermedades y muertes de la infancia. A este respecto puede verse: PERDIGUERO, E. (1995), pp.228, 235-6 y 242.

41 AgRAMONTE, F. (1941b), pp. 79-80.

42 Almansa DE CARA, S. (1941b), pp. 31-32.

43 Ruiz MontosA, P. (1941), p. 50.

44 OLIVA, J.L. (1941a), p. 17.

45 RuIz MontosA, P. (1941), p. 53.
} 
ellas mismas a sus hijos, poniéndoles por el hecho mismo, en trance de enfermar y morir ${ }^{46}$. Las mujeres que justificaban esta conducta con argumentos como que no tenían leche o que tenían poca o no era buena, debían saber que «la madre provista de buen deseo» podía llegar a criar a su hijo; «la leche de la madre siempre es buena para su hijo ${ }^{47}$. En el tema de la lactancia las mujeres eran consideradas tan ignorantes que pecaban por defecto o por exceso, pues «casi la misma resistencia que presentan muchas madres para criar a sus hijos se repite para el destete. Unas veces es por desidia, falta de energía [...] Otras veces prolongan la lactancia creyendo que así no quedarán embarazadas», o por razones económicas ${ }^{48}$. En definitiva quedaba probada la incapacidad de las mujeres para tomar decisiones adecuadas.

La culpabilización llegó a extremos de calificar de inhumanas, incluso inferiores a los animales, a las mujeres que no amamantaban a sus crías, citando a «un eminente médico» de principios del siglo XVIII: «Sólo la mujer [...] es la inhumana que niega a sus hijos el alimento que les debe de derecho natural; sólo ella es la que no tiene entrañas de madre y la que apenas ve a su hijo nacido cuando le quita de su vista y le abandona a las codicias de una mujer mercenaria ${ }^{49}$.

Otro aspecto en el que las madres, por una mala actuación, provocaban importantes alteraciones en la salud de sus hijos era el modo de vestir a los niños. Así se manifestaba: «Da verdadera pena ver como van de abrigados los pequeñitos porque sus mamás no se han decidido aún a rechazar la anticuada manera de vestir a los niños con enormes fajas y numerosas prendas que le impiden los naturales movimientos y la irradiación del calor, haciéndoles sudar y favoreciendo por sobrecalentamiento las diarreas de verano» ${ }^{50}$.

En el discurso higiénico-sanitario analizado, las mujeres no sólo tenían culpas, además tenían deberes en cuyo cumplimiento podían provocar también problemas de índole sanitaria. La mortalidad materna ${ }^{51}$ se producía «en el cumplimiento del deber, por todos conceptos sublime, de dar a la vida un nuevo ser». Y tenía como consecuencia, además de una pérdida para la familia y para el hogar (más importante en los hogares modestos por que produce graves trastornos económicos), un «notable perjuicio para la Sociedad y para el Estado, al dejar cegados esos viveros de ciudadanos, más lamentable que por la pérdida material, por la falta de educación y cuidados maternales de los hijos, que a la postre engendra una fuente imperfecta de ciudada-

46 MARINA, S. (1941b), p. 35

47 MARINA, G. (1941b), p. 46.

48 MOWBRAY BARBERÁN, J. (1941), p. 55

49 MARINA, G. (1941b), p. 47.

50 MARINA, S. (1941b), p. 36.

51 El autor de la conferencia que trató este asunto aseguraba que eran tres mil las mujeres que morían anualmente en España «víctimas de la maternidad», la mayor parte de ellas a causa de infección puerperal. OLIVA, J.L. (1941a), pp. 16-17. 
nía» ${ }^{52}$. La mortalidad materna era un inconveniente «por razones de naturaleza esencialmente puericultora» por encima de las razones demográficas o las «de índole romántica o sentimental», pues estaba «comprobado que más de la mitad de los niños que pierden a su madre durante el primer mes de su vida están fatalmente condenados a perecer» ${ }^{53}$. Así, una vez más, el valor de la vida de las mujeres estaba en función del «otro». La niña no era importante en tanto que llegaría a ser mujer, sino en tanto que sería madre: lo importante en ella era la futura capacidad de reproducir al «otro». La expresión exacta de esta idea apareció en la conferencia de Iniciación a la Puericultura; la importancia del ser humano es tal en tanto que «contiene nada menos que un futuro hombre o una futura madre ${ }^{54}$. Este discurso de género tenía como finalidad hacer sentir a la mujer que la maternidad era la suprema razón de su existencia ${ }^{55}$.

El discurso presente en la campaña de educación sanitaria analizada pretendía dejar claro quiénes eran los responsables de la desventajosa situación en la que se encontraba España. Así, se ejemplificó la «aterradora» mortalidad infantil con cifras de $1932^{56}$, año en que gobernaban republicanos y socialistas. Y se aseguraba que el «orden nuevo» y «los españoles de Franco» que lo habían implantado serían los encargados de cambiar esa realidad ${ }^{57}$.

\section{LAS PREOCUPACIONES DE LOS PROPAGANDISTAS SANITARIOS}

Entre las preocupaciones que de manera explícita o implícita se expusieron en esta campaña de educación sanitaria cabría destacar el componente poblacionista ${ }^{58}$, en tanto que se consideraba que España contaba con una escasa población en comparación a países de su entorno ${ }^{59}$. La causa de esta situación de «inferioridad demográfica» era la alta mortalidad infantil que se había venido dando en el marco de una sociedad regida por el liberalismo ${ }^{60}$. Esta realidad era especialmente preocupante porque se considera-

\footnotetext{
52 Ibidem.

53 Ibidem.

54 AgRAmONTE, F. de (1941b), p. 80.

55 Véase a este respecto JIMÉNEZ LUCENA, I. (1998), «Medicina social, racismo y discurso de la desigualdad en el primer franquismo», en HuERTAS, R.; ORTIZ, C., (eds.) Ciencia y fascismo, Madrid, Doce Calles; especialmente el apartado «Discurso poblacionista «racial» y de género», pp. 122-126.

56 Se sostenía que en 1932 murieron más de 30.000 niños a causa de falta de asistencia tocológica, ausencia de reconocimientos y enfermedades hereditarias, y que el número de abortos declarados oficialmente ascendió a la cifra de 167.000. AGRAMONTE, F. de (1941b), p. 79.

57 Ibidem, pp. 86-89

58 Los aspectos poblacionistas han sido uno de los elementos centrales de las campañas sanitarias de los siglos XIX y XX, como es de sobra conocido. En toda la literatura referida a los movimientos por la salud puestos en marcha puede encontrarse referencias a aquellos.

59 El desarrollo de este argumento puede verse en AGRAMONTE, F. de (1941b), p. 79

60 Ibidem.
} 
ba que «la potencia numérica de nuestras juventudes es la clave del Imperio que anhelamos y que exigen nuestros CAIDOS» ${ }^{61}$. Los niños que morían debían ser salvados para que pudieran «contribuir al engrandecimiento de la Patria» ${ }^{62}$.

Para que España pudiera colocarse «arriba», en el lugar que le correspondía, había que reducir al mínimo las cifras de mortalidad infantil ${ }^{63}$. El objetivo de las conferencias era ese; había que contribuir a la disminución de la mortalidad infantil para que se fuese «repoblando de vidas esta nueva España, para que tengan cumplimiento aquellas palabras del CAUDILLO en su discurso del Año de la Victoria que voy a repetir: «Día llegará que nuestra Patria alcance la cifra de cuarenta millones de habitantes, a los que pueda mantener en completa dignidad, merced a sus poderosos recursos» ${ }^{64}$.

Una preocupación que, en parte, estaba en función de este afán de incrementar la población fue la del trabajo de las mujeres, el llamado «obrerismo femenino», considerado como factor social que producía la «degeneración de la raza» ${ }^{65}$. En principio se exponía que el «obrerismo femenino» había tenido su origen en las necesidades de la postguerra mundial, como «creación transitoria», pero había arraigado como elemento normal del proceso productivo. Además se consideraba que en los tiempos en que se pronunciaba la conferencia el trabajo era para la mujer «una necesidad», dadas las «actuales condiciones económicas», la mujer «debe trabajar» (otro deber más; en ningún caso el trabajo era un derecho para la mujer). Por las razones expuestas, el trabajo femenino no podía ser suprimido bruscamente; habría que contentarse con «remedios menos radicales pero más efectivos», como «atenuar y encauzar su tarea, proporcionarle trabajos menos rudos, más adaptados a su débil organismo y a sus altas funciones maternales». El trabajo que desempeñara la mujer debía ser «especialmente tutelado, higiénico y socialmente protegido». En la consecución de este objetivo debía implicarse el Estado Nacional-Sindicalista «en estrecha colaboración» con el médico, el legislador, el maestro y el Partido ${ }^{66}$.

Se sostenía que el aumento del obrerismo femenino determinaba el descenso de natalidad debido a la «limitación que el trabajo ejerce sobre la capacidad generadora del organismo femenino», produciendo patologías como: clorosis, anemia, enfermedades del sistema nervioso, enfermedades de los órganos pelvianos, predisposición a dolores y hemorragias menstruales, desviaciones uterinas y prolapsos; en definitiva

61 OLIVA, J. L. (1941a), p. 20.

62 MARINA, S. (1941a), p. 5.

63 Ibidem.

64 ALMANSA DE CARA, S. (1941b), p. 34. El afán demográfico de la estrategia sanitaria franquista fue continuamente expresado bajo el slogan que prometía una España de 40 millones de habitantes; a este respecto puede verse MOLERO MESA, J. (1994), «Enfermedad y previsión social en España durante el primer franquismo (1936-1951). El frustrado seguro obligatorio contra la tuberculosis», Dynamis, 14, 199-225, p. 204.

65 OLIVA, J. L. (1941b), p. 21.

66 Ibidem. 
causaba infecundidad ${ }^{67}$. Otros problemas que traía el trabajo era el aumento del número de abortos, partos prematuros y partos distócicos. Además había que hacer notar la disminución del peso medio de los hijos nacidos de madres obreras (sobre todo los de obreras de Industrias y los de empleadas de oficinas), con lo que la mortalidad infantil era mayor entre los nacidos de madres trabajadoras ${ }^{68}$. Por otro lado, existían factores que agravaban los efectos del trabajo sobre la maternidad; factores entre los que se mezclaban, en un mismo plano, las condiciones materiales del trabajo (dureza de las faenas agrícolas, hacinamiento o malas condiciones higiénicas en las fábricas, trabajo con productos tóxicos, nivel de salarios) y elementos socioeconómicos (capacidad adquisitiva, estado de la vivienda, tamaño de la familia) con elementos como el «ambiente moral» o el «grado de educación religiosa» ${ }^{69}$.

Otro de los elementos que estuvo presente en las conferencias analizadas fue la defensa de la institución familiar ${ }^{70}$. Ésta ha encontrado en el discurso de la educación sanitaria uno de sus pilares, pues muchas de las propuestas que manifiesta se basan en una supuestamente imprescindible actuación en el ámbito familiar. Así, en el caso de la conferencia de Salvador Marina sobre normas de higiene general, lo más importante era que los consejos dados no podían ser puestos en práctica «si la madre vive distanciada de sus hijos»; su presencia era indispensable y su vigilancia precisa, y sin ella todo estaría «de antemano condenado al fracaso» $»^{71}$. Porque, como afirmaba otro conferenciante, «la leche y el corazón de una madre no pueden ser reemplazados» $»^{72}$. Además, el amamantamiento era un medio de santificación y de hacer indisoluble la familia ${ }^{73}$. La madre debía ser siempre «cuidadora» de su hijo y su «enfermera» cuando perdiera la salud ${ }^{74}$.

Por otra parte, también se manifestó como un aspecto preocupante, a tener en cuenta, los «peligros de la calle» ${ }^{75}$. Y es que la experiencia pasada, es decir el periodo republicano, había enseñado que los niños necesitaban ser educados adecuadamente. No se debía permitir que los niños «se críen en medio de la calle juguetes de todos los vientos». Por tanto, había que «extender la acción del nuevo Estado Nacional-Sindicalista a la Madre desde el instante en que se pone en trance de serlo» ${ }^{76}$.

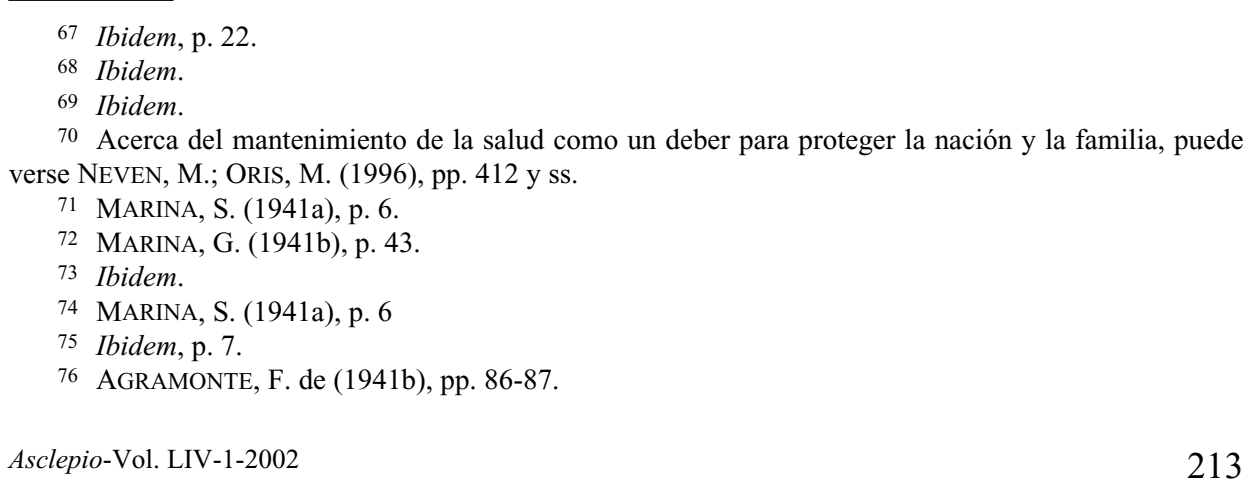


Finalmente, no podía faltar entre las preocupaciones que un grupo de expertos puede sentir la posibilidad de que se valore de forma insuficiente, desde la perspectiva del grupo, la labor y la autoridad de los miembros del mismo. Así, aparecía la frecuente referencia a que no se recurriera a personas no competentes en las materias de la medicina, cuyas actuaciones sólo podían dar lugar a un empeoramiento de la situación por la que se consultaba. En este sentido, se expusieron quejas relativas a que «la mujer de nuestras clases obreras en la región andaluza, con su especial idiosincrasia, su conocida indolencia, su tradicional fanatismo, heredado de los árabes; acostumbra a acoger el embarazo como un acontecimiento natural e intrascendente al que no hay que prestar mayor atención y es difícil de hacerle comprender porqué ha de reconocerla el médico cuando no siente más que las molestias naturales del estado» ${ }^{77}$. Género, clase, etnia, están presentes en este discurso; no se puede expresar de manera más sintética una visión discriminatoria tan impresionante.

\section{CONSEJOS SANITARIOS Y PROPAGANDAS POLÍTICA Y PROFESIONAL}

En la línea de que las actuaciones de los no expertos llevarían siempre al fracaso en la consecución del objetivo pretendido, las únicas soluciones válidas serían, y así fue expuesto, las provenientes de los expertos. Ante todo debía desecharse «la costumbre de hacer uso de los atrevidos consejos de las vecinas, de las amigas o de la abuelita» ${ }^{78}$. Así, se advertía que la adopción de un método de lactancia mixta «bien por que la madre tenga escasa secreción láctea, bien porque padezca una enfermedad debilitante, o porque como decíamos antes, necesariamente tenga que salir a trabajar durante varias horas al día» estaría indicada siempre que «lo juzgue oportuno el médico y siempre bajo su vigilancia» ${ }^{79}$.

Las soluciones eficaces siempre estaban vinculadas a actuaciones de profesionales sanitarios. Así, la disminución de la mortalidad materna que se había experimentado en España desde el primer decenio del siglo XX, cuando era de 50 por diez mil nacimientos, hasta aquellos momentos en que era de 30 por diez mil, había sido consecuencia de la intensificación de la asistencia prenatal a la embarazada y del perfeccionamiento de la asistencia al parto ${ }^{80}$. Todo lo relacionado con el embarazo y el parto debía pasar por las manos de los expertos: actuaciones clínicas pero también preventivas (higiene de la embarazada, régimen alimenticio, instrucciones sobre el

77 OLIVA, J. L. (1941a), p. 17

8 MARINA, G. (1941a), pp. 65-66.

79 Ruiz MonTosa, P. (1941), pp. 50, 52-53.

80 OLIVA, J. L. (1941a), pp. 18-19. 
cuidado del recién nacido) y complementarias como la «investigación sanitaria de la vivienda» que se encargaría a la enfermera visitadora ${ }^{81}$.

La madre no era competente para el cuidado de su hijo porque «el instinto y el cariño maternal [...] no se bastan a sí mismos; la madre, al hacer uso de aquellos, necesita unos conocimientos previos de los principios generales de la higiene» ${ }^{82}$. Pero, para lo que la capacitaría esta formación era para saber cuál era su papel, subordinado al profesional, al experto. Debía saber «qué cosas debe hacer y cuales no cuando su hijo enferma mientras llega el médico, y, una vez en contacto con éste, debe convertirse en su colaboradora eficaz, realizando todo cuanto le indique, no debiendo jamás olvidar que, así como la dirección sólo corresponde al médico, a ella y a nadie más que a ella le corresponde el ser la enfermera de su hijo» ${ }^{83}$.

De esta forma se produjo un doble discurso: por una parte, la responsabilidad en el cuidado del hijo se hacía recaer sobre la madre; por otra parte, la desconfianza en la preparación para realizar esa labor, preparación que no se refería sólo a aspectos «técnicos» sino también a cualidades físicas y morales, llevó a considerar necesaria la intervención de instancias no familiares, institucionales, que cuidaran al niño, salvándolo de los ya mencionados «peligros de la calle» y de la incapacidad de algunas familias. Esta incapacidad unas veces se refería a circunstancias económicas y otras a aspectos ideológicos. Se aseguraba que las «especiales condiciones» que se atravesaban habían agudizado el problema de la falta de medios económicos para realizar los «preceptos de Puericultura» señalados y se hacía necesaria una respuesta institucional: centros para huérfanos, guarderías, jardines de infancia, centros de alimentación infantil, comedores de madres lactantes y otros centros de Puericultu$\mathrm{ra}^{84}$. Y se pregonaba lo siguiente: «vuestro hijo ha de aprender, por de pronto, a sentirse solidario del nuevo orden social [...] capaz de obedecer y de mandar [...] A esos niños hoy, jóvenes mañana, hay que enseñarles fe en Dios y en sus destinos, moral auténtica, culto al Héroe y filosofía de la Historia. Eso, si podéis inculcárselo directamente o con el ejemplo, será lo mejor: si no podéis porque ya os coge viejos y gastados, por lo menos no seáis obstáculo para que lo aprendan en otra parte» ${ }^{85}$.

Esas incapacidades sirvieron como contrapunto a una propaganda en la que se sostenía que a solucionar esos problemas venía el «Estado Español» con mejoras sociales y económicas, y, sobre todo, instituciones como Auxilio Social que proporcionaba alimentos a las madres necesitadas ${ }^{86}$. Un autor que usó de forma muy gráfica este mecanismo propagandístico fue Salvador Almansa. Primero describió un cuadro

81 Ibidem, pp. 19-20.

82 MARINA, G. (1941a), p. 65.

83 Ibidem.

84 MARINA, S. (1941a), p.7.

85 AgramonTE, F. de (1941a), pp. 75-76.

86 MOWBRAY BARBERÁN, J. (1941), p. 55. 
de extremas condiciones para inmediatamente después asegurar que se le estaba dando soluciones desde instancias políticas: «Esos aposentos llamados «salas» en donde numerosos miembros de la familia, comparten no solo el techo, sino también el lecho, que reúnen en la más abyecta promiscuidad los sexos y las edades, repugnan no sólo a la higiene, sino al sentimiento humano, ellos son además de escenario inmoral, asilo de microbios donde la tuberculosis se incuba y se desarrolla por la estrechez de colmena, que favorece y multiplica los contagios, haciendo de ella una enfermedad familiar y de la habitación una pestilente cueva humana que repele a sus propios habitantes. Afortunadamente el Nuevo Estado Español, así lo ha comprendido y entre sus numerosos aciertos va a la cabeza, el impulso creador de la casa sana, de lo que en Málaga somos en estos días testigos, gracias a la iniciativa de nuestro Gobernador Civil, secundado con el mayor entusiasmo por la Falange Española y las clases acomodadas $\rangle^{87}$.

En general, se expuso con entusiasmo la llamada obra social del nuevo régimen ${ }^{88}$, llegándose a señalar que todas las promesas de mejoras sociales estaban encontrando inmediata realidad por «voluntad expresa del CAUDILLO $»^{89}$. Incluso se manipuló la información dada, por conveniencias políticas. Este fue el caso de las referencias hechas al Seguro de Maternidad. De él se dijo que fue organizado por el Instituto Nacional de Previsión en cumplimiento de la ley de marzo de 1929 aprobada durante la «Dictadura del Glorioso General Primo de Rivera» ${ }^{90}$; no se mencionó que fue puesto en marcha en 1931, durante el gobierno republicano-socialista de la II República.

Además se puso cierto empeño en mostrar que las obras sociales del nuevo estado eran esencialmente diferentes a las existentes con anterioridad. Así se expuso una fuerte crítica a las actuaciones del sistema benéfico: «Algunas asociaciones de tipo caritativo se han ocupado parcial y temporalmente de los niños pobres, de algunos niños pobres, en proporción insignificante con respecto a la magnitud del problema. Y en parte se han cansado, pasadas las pomposas ceremonias de la inauguración y de los primeros meses de la novedad, dejando los infelices niños al cuidado de manos mercenarias que, ganando poco, eran incapaces de suplir la exigüidad del beneficio con la satisfacción de la labor cumplida ${ }^{91}$. Frente a este sistema asistencial, se mantenía que, en la fundamental «Obra Suprema de la Reconstrucción de España», la creación de

87 ALMANSA DE CARA, S. (1941b), p.32.

88 Las conferencias en las que se resaltó especialmente la obra social del nuevo régimen fueron: Oliva, J.L. (1941b), pp. 23-24; AlmANSA DE CARA, S. (1941b), pp. 31-34; MARINA, G. (1941a), p. 65; AGRAMONTE, F. de (1941b), pp. 87-88.

Sobre la utilización propagandística de las obras sociales por parte de los vencedores en la guerra civil puede verse: CARASA, P. (1997), «La revolución nacional-asistencial durante el primer franquismo (1936-1940)», Historia Contemporánea, nº 16, 89-140, pp. 95-96.

89 Oliva, J. L. (1941b), p. 24.

90 Ibidem, p. 23-24.

91 AgRAMONTE, F. de (1941b), pp. 79-80. 
instituciones como las de Auxilio Social era una muestra de que el «nuevo Estado Nacional-Sindicalista no quiere pactar con los convencionalismos de antaño» ${ }^{92}$.

En instituciones de este tipo se ejercería una especie de «maternidad social» ${ }^{93}$; por ello, la mujer debía jugar allí un papel imprescindible en la educación del niño, guiándole «hacia los dos grandes ideales de Dios y de la Patria». Realizar esa labor no era fácil, había que «saber hacerlo» ${ }^{94}$. Por ello, el Estado Nacional-Sindicalista de la España de Franco quería enseñarlo a las mujeres encargadas de esa actividad, y las invitaba a seguir «con positivo fervor» los cursillos de Iniciación de Puericultura, organizados por la Jefatura Provincial de Sanidad. A ellas se les aconsejaba: «Pensad que no se trata sólo de saber lo necesario para que el niño que se os confíe sea en su día un hombre ¡lo que entre los españoles bien nacidos se llama un hombre!. No: se trata de que sea algo más: un ser útil a sus semejantes, un digno campeón de los ideales de José Antonio, un fiel soldado de nuestro inmortal Caudillo, jun Falangista, en fin, de la Una, Grande y Libre España Imperial! $\rangle^{95}$. La utilización de charlas y cursillos sobre puericultura para divulgar e inculcar a las mujeres los valores del nuevo estado para que ellas los transmitieran a las niñas y los niños españoles fue parte del programa de actuaciones sociales en el primer franquismo ${ }^{96}$.

Por último, hemos observado que en la campaña educativa analizada no se puso el mismo interés en dar recomendaciones adecuadas a la realidad socioeconómica entonces existente que en pregonar las excelencias del nuevo estado y de la actuación de los expertos. En este sentido, los consejos difundidos sobre hábitos higiénicos en el vestir o el ambiente, así como sobre la alimentación, difícilmente influirían en las conductas de la mayor parte de la población en tanto que no podían ser seguidos, dada la situación socioeconómica padecida. En unos momentos históricos en los que la comida, la vivienda, los productos de primera necesidad escaseaban y eran de difícil acceso, proponer el consumo de sopas, harinas, legumbres, carnes asadas, pescado fresco, jamón, huevos, quesos frescos, nueces, almendras, aguas alcalinas ..., por muy recomendables que fuesen para mantener una boca sana, no pasaría de ser un sueño para la mayor parte de la población española en el año cuarenta. Difícilmente la gran mayoría de la población podría dar a sus hijos cuatro comidas, introduciendo pescados blancos, sesos, carnes magras, mantequillas, legumbres, verduras, frutas frescas, leche, harina, bizcochos, compotas, yema de huevo cruda dos o

\footnotetext{
92 Ibidem, p. 88.

93 Esta cuestión ha sido abordada en nuestro trabajo RUIZ SOMAVILLA, M. J.; JIMÉNEZ LUCENA, I. (2001), «Un espacio para mujeres. El Servicio de Divulgación y Asistencia Sanitario-Social en el primer franquismo», Historia Social, $\mathrm{n}^{\circ} 39,67-85$.

94 Agramonte, F. de (1941b), p. 89.

95 Ibidem.

96 Véase a este respecto JIMÉNEZ LUCENA, I. (1998), p. 113. 
tres veces por semana, en general alimentación variada y rica en vitaminas ${ }^{97}$. Es difícil imaginar cómo a una población que habitaba viviendas como las mencionadas en las primeras páginas de este trabajo, le podrían ser útiles estos consejos: la cuna del niño debía ser fresca, «con colchón de crin, plano, que no se hunda»; la habitación debía ser «la mejor de la casa, la más fresca se le reservará al niño, desposeyéndola de muebles inútiles y difíciles de limpiar. Deberá estar orientada si es posible al mediodía con posibilidades de ventilación perfectas»" ${ }^{98}$; o «la mejor pieza de la casa debe ser el dormitorio del niño, libre de cortinajes y con los muebles indispensables para que se almacene poco polvo y sea fácilmente limpiable» ${ }^{99}$.

Una vez más en una campaña de educación sanitaria se obvió que las elecciones individuales están determinadas en gran medida por las condiciones sociales. Los consejos médico-sanitarios se alejaban de la realidad vivida por la mayoría de la población. Cabría, pues, preguntarse ¿existía una verdadera voluntad de llevar al pueblo información útil para procurarse una vida sana?, ¿realmente se pensaba que la información ofrecida era útil a la mayoría de la población? o ¿se pretendía «crear» una «realidad» distinta que ocultara las condiciones de vida existentes?; es decir, ¿puede ser la divulgación médico-sanitaria un factor enmascarador de los problemas reales?

97 Sobre estas recomendaciones alimenticias pueden verse: ROLDÁN ANDREU, F. (1941), p. 61; MOWBRAY BARBERÁN, J. (1941), pp. 58-59.; MARINA, S. (1941c), p. 71.

98 MARINA, S. (1941b), p. 37

99 MARINA, S. (1941c), p. 71. 